\title{
A CULTURA COMO CONFIGURADORA DE IDENTIDADES NOS SOCIAL GAMES
}

\author{
IDENTITIES AS CULTURE CONFIGURATIONS IN SOCIAL GAMES \\ LA CULTURA COMO CONFIGURADORA DE IDENTIDADES EN LOS \\ JUEGOS SOCIALES
}

Rebeca Recuero REBS

Doutoranda, Universidade do Vale do Rio dos Sinos

rebeca.recuero.rebs@gmail.com

\begin{abstract}
Resumo
O trabalho visa refletir sobre a presença e a atuação dos macroprocessos culturais na constituição da identidade dos jogadores de social games do Facebook. Busca-se compreender como a dinâmica, a estrutura destes aplicativos e as origens sociais dos usuários vão produzir significados capazes de manifestar traços culturais em jogos sociais temáticos no ciberespaço. Para isso, realiza-se uma breve revisão teórica sobre os processos culturais e as tecnologias e depois parte-se para uma observação participante no social game FarmVille do Facebook. Os resultados iniciais apontam os social games como potenciais ferramentas de divulgação, manifestação e formações da identidade cultural do sujeito da atualidade visualizadas em diversos lugares do jogo que permitem movimentos criativos dos usuários.
\end{abstract}

Palavras-chave: Social games. Identidade. Cultura.

\begin{abstract}
This paper aims to reflect about the presence and performance of cultural macroprocess in the identity constitution of the social gamers of Facebook. We seek to understand how the dynamics, the structure of these applications and the social origins os users will produce meanings able to express cultural traits in thematic social games. For this, we make a brief theoretical review about the cultural processes and technologies and then proceed to a participant observation in social game Farmville in Facebook. The initial results indicate the social game as potential tools of dissemination, manifestation and conformation of the cultural identity of today's individualvisualized in various places in the game that allows creative movements of users.
\end{abstract}

Keywords: Social games. Identity. Culture.

Esta obra está licenciada sob uma Licença Creative Commons 


\section{Resumen}

Este trabajo pretende reflexionar sobre la presencia y el desempeño de la identidad cultural global en la constitución de los juegadores de los juegos sociales en Facebook. Tratamos de entender la dinámica, la estructura de estas herramientas y las orígenes sociales de los usuarios producirá significados capaces de expresar los rasgos culturales en los juegos de temática social en el ciberespacio. Para esta, hacemos un breve repaso teórico de los procesos culturales y las tecnologías y después se vá a proceder auna observación participante en el juego Farmville del Facebook. Los resultados iniciales indican los juegos sociales como posibles instrumentos para la difusión, demostración y formación de la identidad cultural de los sujetos de hoy que son visualizadas en diversos lugares de los juegos que permiten a los movimientos creativos de los usuarios.

Palabras-Clave: Juegos sociales. Identidad. Cultura.

\section{INTRODUÇÃO}

A cultura é um indicativo de um conjunto de normas, práticas, crenças, valores, símbolos, linguagens e códigos que são capazes de caracterizar o modo de vida de um grupo ou sociedade (FEATHERSTONE, 1995, p. 179). Estes grupos vão apresentar uma história que é fundada no tempo e atualizada conforme as dinâmicas desenvolvidas pelos atores sociais e suas ações (SANTOS, 1994). Compreende-se então, que a cultura é processual, ou seja, é cultivada e atualizada constantemente ao longo da existência da humanidade, de acordo com seus rumos históricos, econômicos e políticos.

Pensa-se ainda que é de acordo com alguns padrões da cultura que sujeitos pertencentes a uma determinada sociedade estabelecem suas formas de comportamento e seus modos de pensar e compreender processos de significância para práticas sociais que organizam uma sociedade, pois a noção de ação e representação está dada no comportamento social (DURHAM, 1977). Ao mesmo tempo, são estes mesmos sujeitos os responsáveis por parte da fabricação do contexto das relações culturais e sociais (SILVA, 2007). Significa que os processos de formação da cultura e dos atores sociais são indissociáveis, principalmente quando ao compreender as práticas sociais.

No entanto, a produção e o compartilhamento de significados produzidos por uma sociedade e pela sua cultura sofrem a constante atuação da revolução propiciada pelas tecnologias da comunicação que parece introduzir formas diferenciadas de interações sociais (PRIMO, 2007), de experimentações identitárias (TURKLE, 1997), de circulação de 
informações e de produção e valores sociais (RECUERO, 2009). Assim, o sujeito da atualidade se vê cada vez mais possibilitado de ter experiências em um ambiente virtual que interrelaciona diferentes culturas em mesmos sistemas de interação, como no ciberespaço.

Além do rápido e fácil acesso, indivíduos reconhecem outras culturas diferentes da sua e experimentam novos símbolos, valores e identidades capazes de formas novos "eus" de sua personalidade em lugares de interações sociais do ciberespaço (TURKLE, 1997). Compreende-se que o lugar no ciberespaço não apenas é visível como também anuncia simbolismos ligados ao território, estando diretamente associado à necessidade dos sujeitos de expressarem a sua identidade cultural em "outros espaços", diferentes do geográfico, porém fortemente atrelados a ele pelas suas representações (REBS, 2010).

Entre estes diversos lugares virtuais que congregam pessoas do mundo todo partilhando de interesses comuns (como relações sociais) e que partilham expressões (ou elementos) de suas identidades culturais encontram-se os sites de redes sociais.

Segundo boyd e Ellison os sites de redes sociais (SNS) são ferramentas na internet que permitem aos indivíduos (1) construir um perfil público ou semi-público que fica restrito a um sistema limitado, (2) vão articular uma lista de outros usuários com quem estes sujeitos vão partilhar uma conexão, e (3) permitir com que sejam visualizadas as listas de conexões desenvolvidas por todos os usuários do sistema (BOYD e ELLISON, 2007). Assim, os SNS vão dar suporte e permitir a visualização de redes sociais na internet que vão partilhar e difundir informações, a partir da troca de conhecimento entre os membros da comunidade virtual por meio da publicização de suas conexões e contatos na rede. Nestes sistemas não apenas é permitida a atuação do sujeito com uma identidade construída e características visualmente expressadas no perfil do usuário, como existem aplicativos temáticos voltados para o entretenimento que exigem a edificação de identidades fictícias diretamente atreladas às práticas propostas pelo sistema. Entre estes aplicativos, estão os social games.

Os social games ${ }^{l}$ (SG) se caracterizam por serem uma modalidade de jogos desenvolvidos em redes sociais. Eles exigem baixo investimento de tempo do jogador e ainda regras bastante simples. Por possuírem uma temática particular, eles ainda estimulam o desenvolvimento de um personagem que vai agir conforme a dinâmica proposta pelo game. Os SG utilizam

\footnotetext{
${ }^{1}$ Não é o foco deste trabalho discutir o termo social game. No entanto, apesar de serem conhecidos popularmente e simplesmente por "social games" e por eu utilizar esta terminologia no trabalho, questiono a utilização desta nomeclatura, visto que na pesquisa trato de jogos sociais desenvolvidos especificamente em sites de redes sociais, ou seja: "social network games".
} 
informações dos perfis e das relações sociais de seus jogadores, divulgando constantemente informações relacionadas às suas ações no jogo para a rede social do usuário. Além disso, estimulam ações competitivas e cooperativas entre os integrantes de uma mesma rede social.

Mesmo sendo um aplicativo que compreende a visualização clara de certo domínio cultural (por ter empresas responsáveis pelo seu desenvolvimento), pensa-se que é possível observar traços culturais nos SG, pois eles permitem que o sujeito manifeste sua identidade (ainda que de forma limitada devido às opções disponibilizadas pelo jogo) por meio de situações propostas pelo game e ainda através de apropriações realizadas pelos próprios usuários. Busca-se, então, compreender e discutir como traços culturais aparecem e são estimulados pelos e nos social games a partir de um estudo de caso do jogo que se manteve por maior tempo na primeira colocação dos SG mais jogados no Facebook (site de redes sociais mais popular da atualidade): o FarmVille ${ }^{2}$.

\section{PROCEDIMENTOS METODOLÓGICOS}

Visando compreender como a cultura age na constituição da identidade dos jogadores de SG e como ocorre a dinâmica de produção de significados culturais a partir da dinâmica que é proposta pelo jogo, realizou-se uma observação participante por cinco meses (de agosto a dezembro de 2010) em usuários brasileiros do social game FarmVille. Este estudo observacional centrou-se na busca de "rastros" deixados pelos jogadores que pudessem indicar possíveis indícios da identidade cultural. Para isso, foi necessário acompanhar usuários durante o tempo de observação, diariamente, tornando-se uma jogadora também. Fotos e imagens de compras de bens virtuais, de ações destes jogadores e de suas formas de interação (tanto com o jogo, quanto com os outros usuários) foram registradas em um "diário de campo" com a intenção de cruzar estes dados com posteriores informações adquiridas.

Após o período de observação, aplicou-se um questionário (que esteve disponível de 4 de janeiro até 18 de janeiro de 2011) em 140 jogadores de quaisquer SG a fim de compreender os valores culturais manifestados a partir de suas ações nos jogos e com a finalidade de entender os usos e apropriações que eles desenvolviam em objetos do jogo que estavam diretamente vinculados a manifestações da identidade cultural. Este questionário foi

\footnotetext{
${ }^{2}$ O FarmVille perdeu o seu posto de SG com maior número de usuários em dezembro de 2010 segundo dados publicados pela Inside Social Games (http://www.insidesocialgames.com/2010/12/20/cityville-zyngafarmville/?utm_source=feedburner\&utm_medium=feed\&utm_campaign=Feed:+InsideSocialGames+(Inside+So cial+Games).
} 
desenvolvido no Google Docs e distribuído de forma online por diversas plataformas (como o Facebook, o Twitter, o Plurk, etc.). Convidou-se possíveis jogadores de SG a responderem as questões e a repassarem o questionário aos seus amigos, também jogadores. O questionário possuía uma série de perguntas abertas e algumas fechadas com o objetivo de coletar o perfil destes sujeitos.

\section{CULTURA E IDENTIDADE}

Compreendida a partir de processos de ações sociais de significação, a cultura compõe um conjunto de práticas comuns que organizam e regulam a conduta de grupos sociais (HALL, 2000). Além de ser considerada possuidora de uma natureza comunicativa por meio de mediações de conhecimento e reconhecimento, a cultura é por si só atribuidora de características generalizadoras, constituidora de sentimentos de territorialidade (ALBAGLI, 2004) (e construtora de uma identidade cultural que é associada ao sujeito desde o seu nascimento). Esta identidade cultural é compreendida por Stuart Hall como sendo um "sentirse parte de uma nação" (HALL, 2000, p. 47), ou seja, funcionam como "comunidades imaginadas” (p.51), pois a cultura nasce a partir de instituições culturais de símbolos e representações que vão caracterizar e identificar um povo. Desse modo, tradições são passadas de indivíduo para indivíduo com a intenção de manter certa fidelidade às origens capazes de determinar certas ações, moldar significados tanto na vida dos sujeitos como na sua própria história (HALL, 2000, p. 29). Assim, a cultura pode ser pensada como potencializadora de um discurso que constrói sentidos e caracteriza ações com a finalidade de organizar nações e as próprias ideias que os sujeitos possuem de si.

Silva (2007) trata a identidade cultural como sendo o resultado de uma criação. Significa que não são atos naturais, mas sim elementos produzidos, integrantes de um mundo cultural e social. Esta ideia traz a percepção do poder atuando na construção e no pensar as identidades, pois na sociedade existem contextos de relações de poder que são percebidas por meio da própria cultura. Silva aborda exatamente isso ao dizer que:

A identidade, tal como a diferença, é uma relação social. Isso significa que sua definição - discursiva e lingüística - está sujeita a vetores de força, a relações de poder. Elas não são simplesmente definidas; elas são impostas. Elas não convivem harmoniosamente, lado a lado, em um campo sem hierarquias; elas são disputadas (SILVA, 2007, online). 
Desse modo, é possível pensar que a identidade cultural situa-se numa disputa entre recursos simbólicos e materiais da sociedade, pois o sentir-se parte de um determinado grupo inclui a aceitação de normas ou regras previamente decididas por uma escala de poder (seja ele proveniente de consenso coletivo, como de imposições vindas de indivíduos que estão no poder).

Apesar de reconhecer a cultura como uma invenção humana, aceitamos sua imposição "natural" na vida das pessoas que são, de certo modo, pacíficas em aceitá-la e incorporá-la em suas vidas. Assim, reconheço-me brasileira pelo fato de que nasci no Brasil e, quem nasce no Brasil não pode ser outra coisa, senão brasileiro(a). Castells, no entanto, trata a identidade como sendo oriunda de uma demanda de significações sociais, onde as relações entre os sujeitos (com base nos atributos culturais) é que caracterizam as suas identidades, ou seja, a identidade é "o processo pelo qual um ator social se reconhece e constrói significado principalmente com base em determinado atributo cultural ou conjunto de atributos" (CASTELLS, 1999, p. 58).

Jesús Martín Barbero afirmou em uma entrevista dada para a Revista Pesquisa que "a identidade é o que há em comum, ou seja, eu tenho uma identidade jovem, eu tenho uma identidade brasileira, eu tenho uma identidade paulista, eu tenho uma identidade feminina, é o conjunto das religações sociais" (MARTÍN BARBERO, 2009). Já Barros Filho, Lopes e Issler (2005, p.19) definem a identidade como sendo "o resultado provisório de um diálogo entre o social e o sujeito", o que indica a necessidade de se compreender não apenas questões particulares dos sujeitos para se entender a sua identidade, mas também a sociedade na qual ele está inserido. Denotam que é essencial levar-se em conta os processos sociais, a história, as tecnologias inscritas na vida social e a própria cultura para ser possível obterem-se pistas identitárias do sujeito em análise.

Scott, inclusive, afirma que a nossa identidade é organizada em torno das nossas "histórias de vida" que vão constituir "formas de vida" que serão "modos de vida" (SCOTT, 2005, p. 39). Isso sugere a necessidade desta multiplicidade de fatores externos aos sujeitos (como a própria mídia) para a constituição de sua identidade que é diretamente estabelecida pela forma de vida do sujeito atrelada à sua história, à sua cultura, aos integrantes de seu grupo e aos seus bens simbólicos.

Entretanto, os efeitos da globalização contemporânea parecem apresentar certa tendência à homogeneização a partir de uma cultura dominante e, ao mesmo tempo, produzem formações 
subalternas que, de certa forma, agem contra a suposta "homogeneização" (HALL, 2003, p. 59 - 60). Significa que ao mesmo tempo em que observamos certa necessidade à homogeneização do mundo pelos valores culturais e de consumos mundializados, verifica-se que há uma proliferação das diferenças, caracterizando o paradoxo da globalização.

A partir disso, enfatiza-se a importância de se analisar as identidades culturais do homem moderno sempre levando em consideração dois processos: o de homogeneização e o de diferenciação (SANTOS, 1994). Desse modo, ao mesmo tempo em que os indivíduos buscam enquadrar-se em grupos sociais partilhando de uma mesma identidade (visualizada pelo comportamento, simbolismos, rituais e bens comuns adquiridos) (SCHERER-WARREN, 1999), tem-se uma sujeito que busca ser diferenciado, constituindo uma "identidade única" (visualizada por meio de personalizações de gostos, de valores, de comportamentos e, também, por meio da aquisição de bens simbólicos diferenciadores).

A percepção da diferença (o reconhecimento do outro como sendo diferente da minha identidade) pressupõe a existência de certa homogeneidade, o que permite com que o sujeito se reconheça quanto integrante de uma determinada identidade coletiva e, ao mesmo tempo, perceba as diferenças que existem com integrantes de outros grupos sociais diferentes (SANTOS, 1994, p. 239). Desse modo, a identidade une pelas semelhanças e separa pelas diferenças.

No entanto, ao pensar as identidades, Hall (2000) prefere o termo "identificação" pelo fato de que a identidade encontra-se em uma processualidade, ou seja, o sujeito possui uma identificação que é construída e moldada ao longo de toda a sua vida e não apenas uma identidade única, acabada e fechada. Além disso, a própria identidade cultural não existe de forma independente ou isolada, mas sob a influência de várias culturas, anteriores e contemporâneas a ela, que estão na origem ou influenciam seus valores e costumes (HAESBAERT, 2007) Isso implica na "experimentação" de inserção do sujeito em novas culturas, compondo assim mais uma de suas múltiplas identidades.

Com as tecnologias da informação e da comunicação esta multiplicidade de identidades de cada sujeito parece ficar ainda mais visível e ainda mais estimulada, pois usuários da Internet se veem necessitados de refletir sobre si ao serem solicitados a criarem seus perfis em diferentes lugares virtuais como sites de redes sociais, blogs, salas de conversação e jogos. Além disso, ambientes voltados para a imaginação e criação solicitam construções de identidade que não se vinculam necessariamente com as identidades que o sujeito apresenta 
na vida concreta, exigindo assim, a criatividade sobre o que se gostaria ser em um mundo fantasioso. No entanto, mesmo nestes lugares virtualizados vão existir culturas dominantes que legitimam determinados comportamentos, práticas sociais, regras e impões determinados tipos de bens simbólicos que serão buscados pelos integrantes destes grupos sociais (BOURDIEU, 1974). Estes grupos vinculam-se a lugares virtuais de fácil acesso voltados para interações sociais com sujeitos potencialmente provenientes do mundo todo (como sites de redes sociais e jogos).

\section{O SOCIAL GAME FARMVILLE}

Os SG são caracterizados por serem estilos de jogos desenvolvidos em redes sociais que estimulam a competição e a cooperação entre os atores. Para definir jogos parte-se da concepção de Huizinga que diz que jogos são:

(...) uma atividade ou ocupação voluntária, exercida dentro de certos e determinados limites de tempo e de espaço, segundo regras livremente consentidas, mas absolutamente obrigatórias, dotado de um fim em si mesmo, acompanhado de um sentimento de tensão e de alegria e de uma consciência de ser diferente da vida quotidiana (HUIZINGA, 2000, p. 33).

Os SG são uma atividade voluntária, onde usuários cadastram-se no aplicativo por livre e espontânea vontade a fim de jogar. Possuem seus limites de tempo e espaço (ainda que virtuais e focados no site de redes sociais suporte) e possuem suas regras específicas, envolvendo sentimentos de busca por objetivos e recompensa ao alcançá-los. Também são facilmente identificados como um "lugar" que não é vida concreta, algo que representa, que simula fatos em um ambiente virtual. Por isso, considera-se como modalidades de jogos (dentro da concepção de Huizinga) desenvolvidos em um ambiente virtual. Estes jogos sociais na internet ainda permitem com que as informações relativas ao game sejam divulgadas nas atualizações públicas da rede social do usuário. Além disso, os SG utilizam as informações e relações sociais disponibilizadas nos perfis dos atores da rede. Eles possuem regras e normas centradas na temática particular de cada jogo (fazenda, polícia, zoológico, circo, etc.), o que exige com que ocorra o desenvolvimento de um personagem também temático. São caracterizados por serem voltados para a atividade recreativa (entretenimento) e por serem 
jogos casuais (TAUSEND, 2006 e RAO, 2008), pois exigem baixo tempo de dedicação e possuem regras relativamente simples.

Selecionou-se o SG FarmVille (da empresa Zynga) para a observação por ele ser (durante o período da pesquisa) o SG de maior sucesso no Facebook. Por ser um SG consolidado (existente desde junho de 2009), além de ele apresentar inúmeras possibilidades de objetos decorativos, variados elementos de personalização, o FarmVille ofereceu temáticas particulares referentes a festas culturais aos seus usuários que eram disponibilizadas de acordo com a data coincidente no universo concreto. Assim, conseguiu-se uma gama de possíveis amostras capazes de caracterizar facetas identitárias dos seus usuários.

O FarmVille é caracterizado por ser um jogo onde o ator social é um fazendeiro (o jogo simula uma fazenda), ou seja, ele realiza ações centradas no plantio, na colheita de verduras e legumes e no cuidado de animais (como cavalos, vacas, ovelhas e galinhas) em tempo real. $\mathrm{O}$ objetivo é evoluir e acumular moedas virtuais para poder adquirir bens virtuais. Quanto mais tempo o sujeito dedica ao jogo, mais ponto de experiência ele adquire e vai melhorando a sua posição em um ranking composto por todos os seus "vizinhos" (os amigos da sua rede social do Facebook que jogam o FarmVille). Os melhores colocados liberam itens novos e adquirem uma série de benefícios que em posições menores não é permitido.

O usuário pode decorar e construir a sua fazenda como deseja no jogo. Ele ainda deve cumprir determinadas "missões" estipuladas pelo aplicativo e colaborar na manutenção da fazenda de seus "vizinhos". Quanto melhor o jogador se sai nas suas tarefas, mais dinheiro virtual $^{3}$ ele adquire e, assim, pode comprar mais bens virtuais para a sua fazenda (como casas, tratores, flores, animais exóticos, etc.). Ainda há a presença do "FarmVille Cash", uma moeda especial que permite aos jogadores comprarem alguns elementos de decoração exclusivos. Porém para a aquisição do Farm Cash é preciso o investimento de dinheiro "real" (dólares).

Constantemente o Famrville disponibiliza novos itens para os jogadores comprarem, bem como atualiza-se conforme as datas festivas, oferecendo assim uma gama contínua de objetos que ficam à disposição do gosto (e do dinheiro virtual) de cada jogador. A partir destas possibilidades de decoração da fazenda, de "escolha" do que comprar (seja por meio de dinheiro virtual ou "real"), ou ainda de como construir o seu avatar, tenta-se encontrar traços que apontem para traços culturais de brasileiros jogadores deste SG.

\footnotetext{
${ }^{3} \mathrm{O}$ dinheiro virtual se caracteriza por uma moeda que tem validade apenas no jogo. No entanto, é possível utilizar dinheito concreto (dinheiro "real") para adquirir (comprar) mais moedas deste dinheiro virtual, o que permite com que o jogador possa alcançar fases, itens, bens e outras ações no SG com mais facilidade.
} 


\section{IDENTIDADES CULTURAIS NO FARMVILLE}

Como apresentado anteriormente, o FarmVille é propriedade do Facebook e foi desenvolvido pela companhia Zynga que é a responsável por produzir os itens virtuais de elementos de jogo, bem como suas regras. Ambas são empresas estadunidenses. De certo modo, pode-se refletir sobre a presença de uma cultura dominante (vinculada ao mundo externo) na estipulação de como o jogo vai se desenvolver. Assim, pode-se pensar que no FarmVille há a supremacia de uma cultura dominante que prioriza e seleciona quais bens virtuais estará disponibilizando no aplicativo.

Com base na breve revisão bibliográfica apresentada anteriormente, propõe-se realizar a análise da atuação da cultura na constituição e manifestação identitária do jogador do social game FarmVille, a partir de dois focos defendidos por Boaventura de Souza Santos (1994) e por Stuart Hall (2003): a diferenciação e a homogeneização das identidades culturais. Desse modo, selecionou-se aspectos característicos do jogo que indicam "lugares de criação" dos usuários, caracterizados como sendo ambientes que oferecem certa liberdade para as manifestações inventivas (e culturais) dos sujeitos, não sendo puramente restritos a normas do sistema (o que facilita tanto a representação da identidade individual quanto da identidade coletiva). Estes "lugares de criação" do SG são: o território virtual, o self, os bens virtuais simbólicos e as interações sociais, conforme descreve-se a seguir:

\section{a) O território virtual}

O território virtual se caracteriza por ser um lugar apropriado, ou seja, um lugar (portador de uma identidade, de uma historicidade particular e de tipos de interações características) que é tornado posse de um determinado sujeito (REBS, 2010). Significa que o território é visualizado quando há o desenvolvimento dos sentimentos de pertença e posse, estipulando regras e relações de poder por parte dos sujeitos que interagem no e com o lugar. Este território, no entanto, pode ser observado no universo virtual quando estes mesmos sentimentos são desenvolvidos sobre um lugar também virtual.

No SG FarmVille, o território é claramente visto por meio da propriedade (fazenda virtual) que cada usuário possui e constrói. Nestas propriedades os jogadores têm a liberdade de distribuir os itens que compram e decorá-la da maneira que querem. Desse modo, a construção do território virtual torna-se um diferenciador identitário quando se pensa na 
individualidade e personalização desenvolvida pelo usuário. Este diferenciador atua na visualização da identidade cultural do sujeito jogador que usa ou se apropria de elementos do jogo mostrando "traços" do seu eu, conforme se observa nas imagens a seguir, coletadas pela pesquisadora a partir da observação de construções de jogadores do FarmVille.
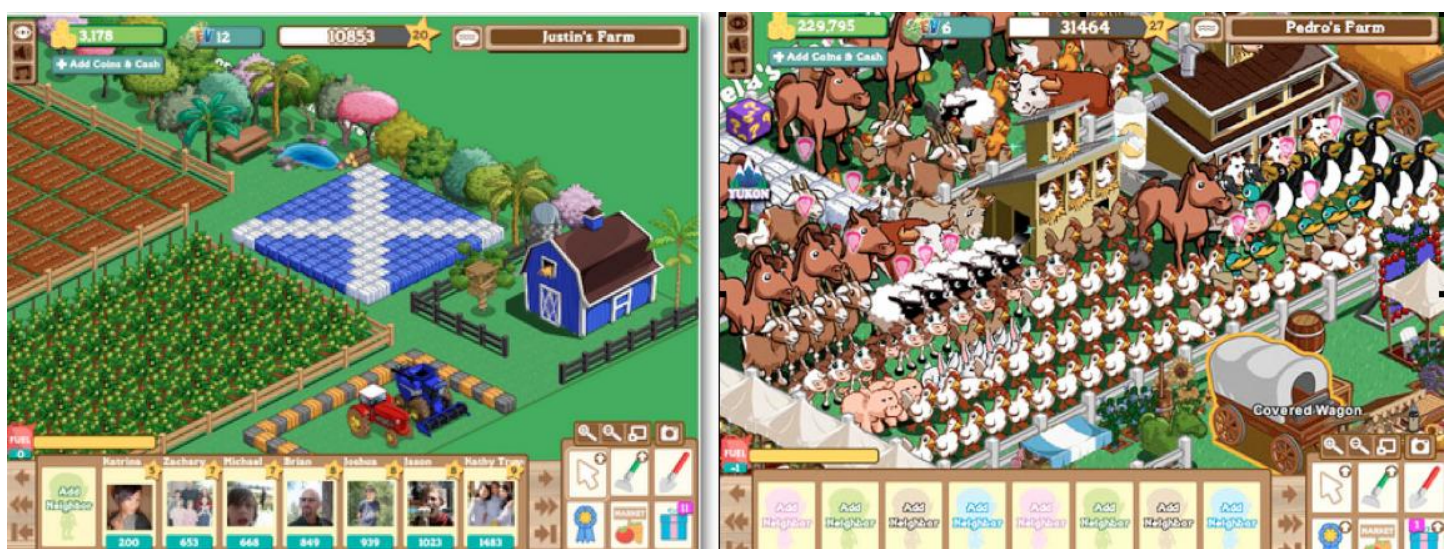

Figura 1: Fazenda decorada com a bandeira da Escócia feita com fardos de palha colorida e outra fazenda repleta de criação de animais (distribuídos uniformemente em linhas).
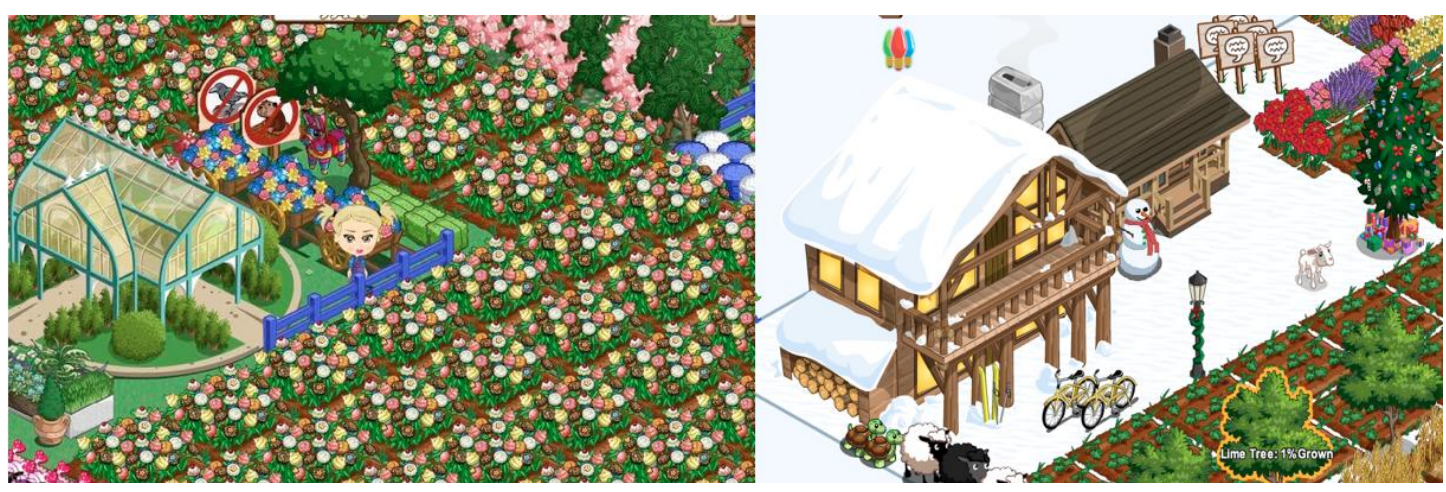

Figura 2: Fazenda repleta de plantações de Cupcakes e outra fazenda criada na neve.

Observando estas fazendas virtuais, verifica-se a personalização da fazenda virtual como um diferenciador identitário, ou seja, usuários constroem bandeiras (que podem ser indicativo de sua identidade nacional); distribuem elementos extremamente alinhados em sua fazenda (podendo ser um indicativo da produção industrial, outra faceta que pode caracterizar a cultura identitária de um sujeito); criam uma fazenda de Cupcakes $^{4}$ (o usuário tanto pode ser um adorador deste tipo de bolo, como também pode ser originário da cultura britânica) ou ainda desenvolvem a sua propriedade em um "clima" dos pólos.

\footnotetext{
${ }^{4}$ São tipos de "bolinhos ingleses" bastante populares.
} 
No entanto, o território virtual pode ser um fator de homogeneização a partir das possibilidades limitantes que o aplicativo oferece aos jogadores. Não há elementos infinitos ou a oportunidade de criação de novos itens para o jogo. Significa que é dentro de uma ação limitante de objetos que o jogador vai construir seu território e deixar possíveis "rastros" de sua identidade cultural. Ou seja, as fazendas possuem duas ou três possibilidades de vegetação (neve, gramado ou deserto), árvores frutíferas, animais, formas de personalização de suas residências com número limite e, ainda, limites espaciais.

Entretanto, mesmo com as possibilidades de construção diferenciadora de seu território, muitos integrantes costumam organizar a sua propriedade de maneira bastante semelhante (como animais “presos” em cercas, plantações em áreas comuns, pomares com diferentes árvores frutíferas em uma mesma região, porcos no chiqueiro). Isto aponta para comportamentos "padrões" que parecem institucionalizar (ou naturalizar) certas práticas sociais como sendo o "correto", o tradicional característico da identidade de "fazendeiro".
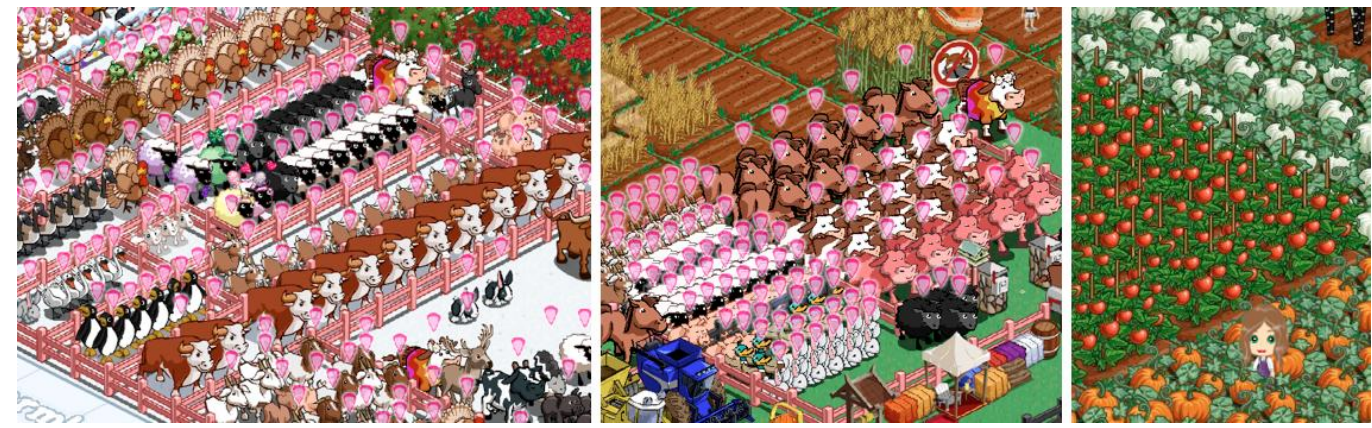

Figura 3: Três fazendas diferentes que apresentam uma forma homogênea de distribuição dos animais da fazenda (cercados por uma cerca) e de plantações distribuídas por tipos em uma mesma região.

\section{b) O self virtual}

O "eu virtual" vai se caracterizar no FarmVille por ser representado por meio do avatar ${ }^{5}$ que é construído pelo usuário. Este avatar terá uma identidade característica que, ao mesmo tempo em que busca se diferenciar dos outros por meio de itens, segue certo padrão estipulado pelo jogo. Isto é verificado por meio da observação das características diferenciadoras (como a cor do cabelo, cor dos olhos, boca e sexo). Porém, roupas seguem um padrão: todos estão de macacão (a roupa mítica de fazendeiros) e estão divididos por cores (mulheres de roxo e

\footnotetext{
${ }^{5}$ Compreende-se o avatar neste texto como sendo uma representação virtual de si, ou seja, são "compostos de dois elementos: um elemento referente ao software (o corpo gráfico criado ou utilizado pelo usuário para representá-lo no ambiente de conversação virtual) e um elementohumano (o próprio usuário que interage através do corpo gráfico)" (RECUERO, 2000).
} 
homens de azul). Para ser possível diferenciar ainda mais o seu avatar dos outros jogadores, é necessário utilizar dinheiro virtual, prática que é comum a $11 \%$ dos jogadores de SG de acordo com respostas dos usuários ao questionário.
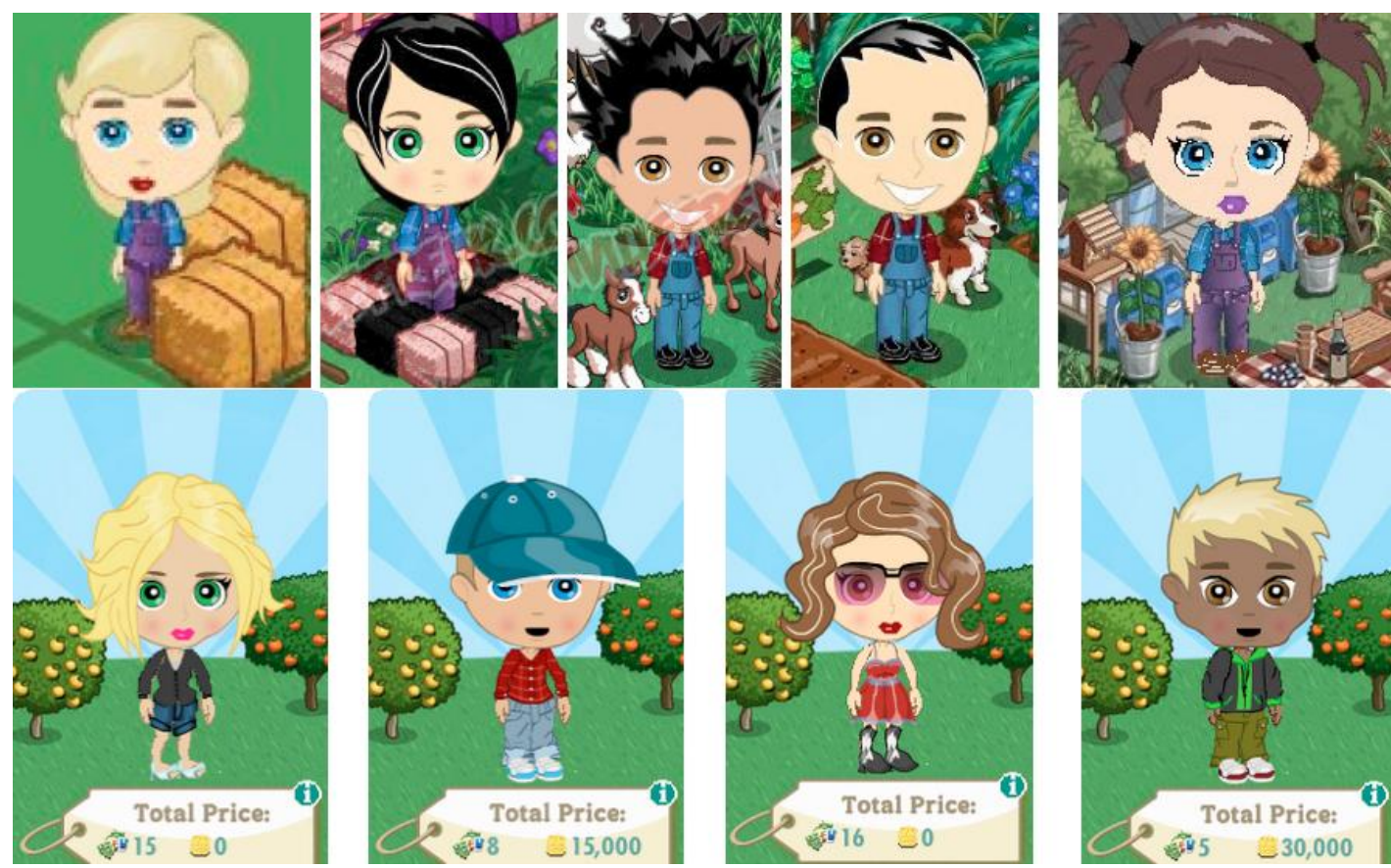

Figura 4: Avatares "padrões" do FarmVille (na primeira coluna) e avatares com roupas personalizadas (segunda coluna).

Desse modo, os jogadores se constroem como gostariam de ser (ou o mais próximo possível do mundo concreto) buscando uma diferenciação identitária e, ao mesmo tempo, sendo fortemente influenciados por fatores culturais que determinam gostos, a moda e a sua apresentação virtual.

A raça é outro fator que se visualiza na representação identitária da criação do self virtual. Ela está diretamente ligada à identidade cultural, onde o discurso genético é materializado em características corporais que são visíveis como a cor dos olhos, a cor a pele, o formato do nariz, o tipo de cabelo ou o formato das orelhas. Segundo Hall (2003, p. 70), esta compreensão da raça permite seu funcionamento enquanto mecanismos de fechamento discursivo em situações cotidianas, o que indica a etnicidade como um fator que é construído a partir de características físicas que se tornam distinguíveis. 


\section{c) Os bens virtuais simbólicos}

Bens virtuais se caracterizam por serem itens virtuais (elementos formados por pixels) que são de posse (ou propriedade) de algum usuário que os adquiriu em troca de um pagamento (seja ele virtual, simbólico ou concreto) com a intenção de usufruir em um espaço virtual (REBS, 2011). Normalmente bens possuem valores ligados diretamente á estética e a valores sociais (HAUG, 1997) que parecem estabelecer identidades no ciberespaço. São mercadorias valorizadas por grupos sociais, repletas de significações e expressões de representação dos sujeitos (BOURDIEU, 1974) que vão conferir certo benefício social (ou funcional) no ciberespaço, centrando-se ainda em suprir desejos particulares dos seus proprietários, desejos coletivos, ideais de diferenciação (REBS, 2011).

Os bens serão fatores importantes para determinar identidades, seja como artefatos de homogeneização ou de diferenciação. Bens de diferenciação são bens capazes de sobressaltar indivíduos (em algum aspecto) dentro de seu próprio grupo social (BOURDIEU, 1974). De acordo com os usuários que responderam ao questionário, $67 \%$ costumam personalizar suas propriedade ou avatar com a intenção de identificar-se, de diferenciar-se dos outros jogadores. Já bens adquiridos com a intenção de homogeneizar sujeitos provêm de valores preconizados pela sociedade, impondo desejos de consumo e significados aos bens que são adquiridos e valorizados por determinados grupos sociais.

Como diferenciador dentro dos SG, verificamos a aquisição de bens que atribuem desejos coletivos, funcionando como bens de reputação social (bens virtuais que são valorizados pelo grupo) ou ainda bens funcionais (bem ligado à função que o objeto possui dentro do jogo). Ter um espantalho, por exemplo, implica em ter 15 FarmVille Cash. De certo modo, adquirir este bem virtual para a sua fazenda pode indicar reputação para o jogador (jogador que possui dinheiro virtual - ou até mesmo "real”, jogador que está em nível avançado ou ainda um item que deixa a fazenda virtual mais bonita). Do mesmo modo, ter um cavalo caro implica em reputação e em retorno "financeiro", eventualmente a partir do cavalo.

Existem bens que apontam para a identidade nacional como as bandeiras, por exemplo. Ao mesmo tempo em que adquirir uma bandeira como um bem virtual que irá identificar o

\footnotetext{
${ }^{6}$ Retorno "financeiro" referente à fazenda virtual, ou seja, adquire-se mais dinheiro virtual do jogo e para ser utilizado no jogo.
} 
jogador atua como forma de diferenciá-lo de outras identidades nacionais no jogo, a simbologia da bandeira nacional enquadra o jogador em um grupo social, homogeneizando assim, parte de sua identidade por meio de um bem adquirido. Do mesmo modo itens referentes a uma cultura (como animais característicos de um determinado lugar, estilo das casas) podem indicar a identidade cultural por meio do jogo.
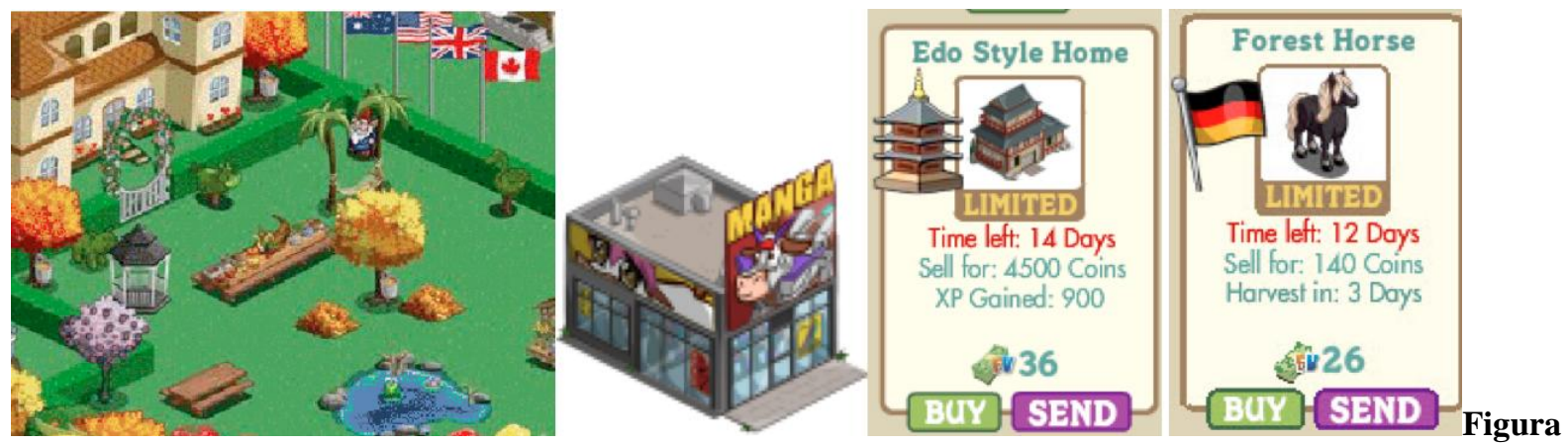

5: Fazenda com bandeiras de países; duas casas características de uma cultura (japonesa) e cavalo originário da Alemanha.

Os bens virtuais homogeneizadores, além de se caracterizarem pela semelhança entre os itens (ou seja, são bens peculiares de uma fazenda), há itens que apontam para festas culturais comemoradas no mundo todo. Assim, o Natal, o Ano Novo e a Páscoa (por exemplo) implicam na disponibilidade de novos bens virtuais que são adquiridos pelos usuários.

Cerca de $39 \%$ dos jogadores costumam comprar bens virtuais que envolvem eventos culturais como as festividades de Natal, Ano Novo, Dia dos Namorados ou ainda símbolos (como bandeiras, casas, fauna e flora característica) referentes aos seus países de origem para decorarem a sua propriedade (dado obtido do questionário aplicado aos jogadores). Esta atitude parece manifestar uma identidade cultural por meio da aquisição de bens que são apreciados por grupos que partilham de uma identidade comum.

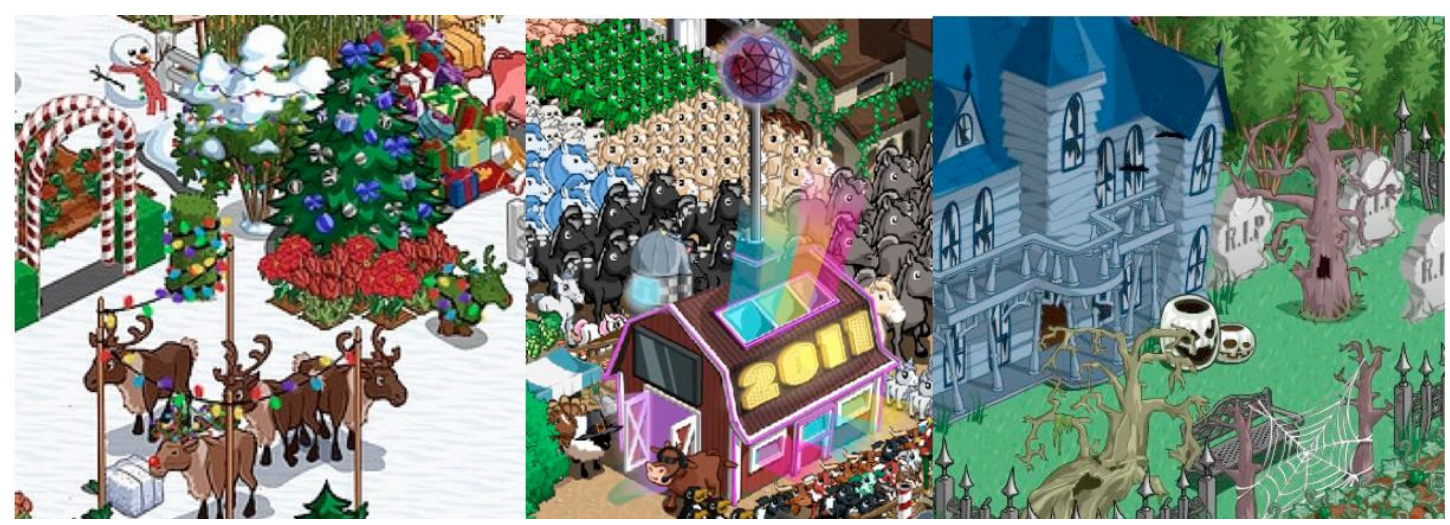

Figura 6: Itens comemorativos a festas populares no FarmVille - Natal (renas, árvore de Natal, neve, presentes); Ano Novo (estábulo enfeitado com luzes) e Dia das Bruxas (casa abandonada, cemitério, teias de aranha). 
Estes bens são adquiridos por comporem sentidos simbólicos que serão atrelados ao seu proprietário. Assim, o aplicativo parece estar constantemente oferecendo bens capazes de caracterizar uma cultura em particular a fim de que os seus usuários adquiram estes itens como forma de manifestar (ou construir) suas identidades.

Furtado, ao tratar da identidade nacional, realiza uma crítica ao "consumo" cultural de outros países. Isto causaria uma homogeneização dos desejos e identidades, pois parece ser capaz de hibridizar e possibilitar certa "perda" de identidade nacional. Seria o caso, talvez, da busca pela aquisição de bens que se apropriam de festas provenientes de outras culturas (como Halloween ou a presença de neve no Natal de brasileiros). Laclau (1996), no entanto, mesmo compartilhando da idéia de Furtado de que os processos de globalização e as tecnologias estariam gerando uma mescla entre identidades, parece não concordar que possa existir uma "perda identitária".

Essa universalização e seu caráter aberto certamente condenam toda identidade a uma inevitável hibridização, mas hibridização não significa necessariamente um declínio pela perda de identidade. Pode significar também o fortalecimento das identidades existentes pela abertura de novas possibilidades. Somente uma identidade conservadora, fechada em si mesma, poderia experimentar a hibridização como uma perda (LACLAU, 1996).

Estas aquisições nos SG passam a existir de forma puramente simbólica (e virtual), transformando-se em elementos capazes de constituir "novos" sujeitos e novos sentidos de desejos em torno deles, manifestando identidades características de uma cultura.

\section{d) As interações sociais}

Interações sociais visando um valor social comum no jogo são características de uma identidade homogeneizadora. Assim, os jogadores possuem propósitos semelhantes (decorar a fazenda, evoluir no jogo, superar amigos no ranking, fazer coleções de bens que lhe agradam) e que são partilhados por diversos usuários do FarmVille. Há então, certa uniformização dos padrões de comportamento no jogo. Estes padrões são estabelecidos pelas regras e limitações que o aplicativo possui. Desse modo, a identidade cultural de cada jogador pode manifestar sua liberdade em um limite de opções que o jogo dispõe. 
Envio de gifts, a visita diária à fazenda dos vizinhos, a plantação, a colheita de seus produtos e a solicitação constante por ajuda aos amigos são práticas comuns que caracterizam interações sociais homogeneizadoras. Significa que quem é um jogador do SG FarmVille terá estas atitudes pois partilha de valores comuns e, então, interage conforme padrões de comportamentos e dinâmicas sociais esperadas pelo seu grupo de pertença.

Mata (2001) trata das tecnologias como configuradoras de identidades e configuradora de novos hábitos, o que significa que a partir das interações desenvolvidas em universos virtuais temáticos que exigem certos "padrões" de comportamento (como o caso do SG FarmVille), os sujeitos vão construir suas identidades a partir de interações "previstas" pelo sistema. Estas interações, entretanto, podem ser apropriadas apresentando traços identitários individualizados dos jogadores. Desse modo, observou-se a presença de lugares de criação nas interações desenvolvidas por meio da linguagem que parecem expressar fortes sentidos culturais. Segundo Habermas, a língua por si só, já é uma característica particular de uma identidade coletiva, pois expressa participação, inclusão dos sujeitos às interações sociais.

A identidade do indivíduo está entrelaçada às identidades coletivas e pode ser estabilizada apenas em uma rede cultural que, tal como a língua materna, não pode ser apropriada como propriedade privada. Consequentemente, o indivíduo permanece na qualidade de portador de "direitos a participação cultural (HABERMAS, 1994 apud HALL, 2003, p.81)"

O direito de participação cultural a partir da língua é vetado a alguns jogadores, pois é necessário saber o inglês para ter o entendimento perfeito do jogo. No entanto, existirão apropriações e esforços de outras culturas atuantes no game para conseguirem participar da dinâmica do jogo.

Como em qualquer outro social game, o FarmVille permite a publicação de informações prontas referentes ao jogo para a toda a rede social do jogador. Significa que mesmo as pessoas que não jogam, terão acesso a estas informações. Para compreendê-las, é necessário se ter o domínio do inglês. Estas técnicas discursivas vão indicar relações de poder (COCKBURN, 1996), o que indica, novamente, a soberania de uma identidade cultural que tem domínio no game. Santos diz que este mecanismo se caracterizaria como sendo a presença de uma identidade dominante que é reproduzida por dois processos distintos: o de "negação total do outro" e o da disputa com a identidade subalterna do outro" (SANTOS, 1994, p. 250). A língua acaba por tornar-se uma característica cultural limitante do aplicativo, 
que revela a necessidade de adequação do sujeito ao sistema ou a busca por apropriações no jogo que permitam-no participar do processo.

Entretanto há o espaço para que usuários possam escrever algo na mensagem, o que implica na manifestação da língua quanto lugar de criação e de manifestação cultural no SG.

Como fator de diferenciação da identidade cultural, verificamos as diversas línguas que são escritas nestes pequenos posts do jogo para a rede social. As pessoas apropriam-se do espaço como forma de manifestar mensagens para usuários que partilham de uma mesma cultura e que compreenderão o envio do post (mesmo que não sejam falantes do inglês).
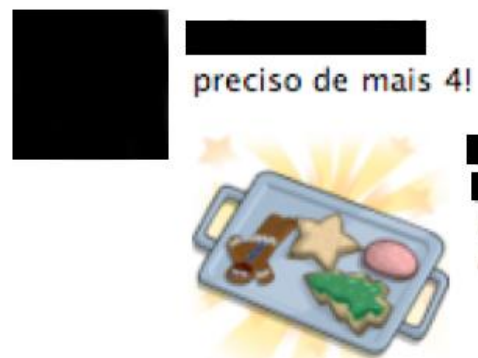

needs some Holiday Treats in FarmVille! needs some Holiday Treats to make sure they're ready to entertain for the holidays! Be a good friend and give them one -- you'll get one too!

Figura 7: Mensagem postada nas atualizações do Facebook (disponíveis para a rede social do jogador) que mostra o uso da língua portuguesa como forma de comunicação com usuários também falantes do português.

Mata (2005) trata dos públicos ao dizer que eles vão constituir uma história "base", ou seja, um modo identitário onde os indivíduos se reconhecem a partir de suas formas de atuação na sociedade. Significa que mesmo não conhecendo a língua dominante do aplicativo, os jogadores compreendem as informações pela sua trajetória no jogo que é partilhada por uma identidade e objetivos comuns. Desse modo, interagem por meio da sua linguagem que é uma característica comum da sua cultura e ainda buscam familiarizar-se com a linguagem do sistema para conseguirem evoluir no jogo.

Assim, a partir destes lugares de criação, verifica-se que há a manifestação identitária característica da cultura particular de usuários do SG FarmVille, visualizadas não apenas em ações voltadas para a diferenciação como para a homogeneização de suas identidades culturais. Este esforço parece indicar uma necessidade de afirmação de valores simbólicos que são representados, também, em um universo virtual. 


\section{CONSIDERAÇÕES}

Desenvolveu-se uma breve revisão teórica sobre fatores culturais e as duplas vias de afetações entre a constituição da cultura e as identidades dos sujeitos que vivenciam e partilham de valores coletivos em suas práticas sociais. Com base nestas teorias, focou-se o processo de compreensão da existência de possíveis manifestações culturais configuradas pelo ator social integrante de SG e das próprias normas e limitações do aplicativo voltado para o entretenimento em site de redes sociais.

Para tanto, desenvolveu-se uma observação participante por quatro meses no social game FarmVille e a aplicação de um breve questionário em 140 usuários de variados SG com a intenção de compreender como a dinâmica, a estrutura, a organização e os significados simbólicos de elementos de jogos sociais poderiam apresentar traços da identidade de seus jogadores. Do mesmo modo, buscou-se visualizar as ações desenvolvidas pelos usuários do FarmVille para manifestarem suas práticas no jogo como possíveis indicadores de traços culturais expressados por meio dos usos e apropriações da ferramenta.

Verificou-se que vão existir "lugares de criação" nestes aplicativos caracterizados pela atuação e pelas apropriações inventivas de usuários que podem indicar espaços de revelação identitária de cada sujeito no game. Então, selecionou-se alguns "lugares de criação" dos SG caracterizados por oferecem certa liberdade para manifestações inventivas dos jogadores (não restritas puramente às normas do sistema) e buscou-se encontrar "rastros" de uma identidade cultural. Estes lugares são: o território virtual, o self, os bens virtuais simbólicos e as interações sociais.

Apesar das restrições limitantes dos SG, observou-se que a identidade cultural é apresentada tanto sob a forma de homogeneização como na de diferenciação do ator social nestes games. Nos territórios virtuais, as formas de construções, decorações e apropriações do espaço, ao mesmo tempo em que revelam identidades coletivas (como a caracterização padrão de uma fazenda) mostram particularidades culturais do jogador (como ter a construção de uma bandeira com fenos coloridos em sua fazenda).

A construção do self implica não apenas na representação e busca por diferenciação do sujeito dos outros jogadores por meio de características físicas escolhidas e atribuídas para compor o avatar (como tom de pele, cor dos olhos e do cabelo), como também na partilha de valores comuns expressos nas vestimentas características de um fazendeiro, impostas pelo game (o que, de certa forma, homogeneíza o jogador). 
Observou-se que com os bens virtuais simbólicos, usuários diferenciam sua propriedade em busca de reputação e do reconhecimento através da aquisição de itens valorizados pelo seu grupo de interação, o que de certa forma também os enquadra em um perfil cultural de consumo já existente. Ao mesmo tempo, os jogadores buscam valores coletivos ao comprar bens que valorizam festas tradicionais (como o Natal, por exemplo).

Verificou-se também que a língua é um fator importante para manifestar a identidade cultural nestes SG. Ao mesmo tempo em que há uma cultura vigente, dominante no aplicativo, usuários apropriam-se dos espaços de manifestações disponibilizados pelo próprio SG para manifestarem-se em sua língua materna, gerando assim, interações mais fáceis com sujeitos que partilham de uma mesma cultura ou que não compreendem o inglês.

Estas novas formas de interações sociais manifestadas através da internet, ainda que voltadas para o entretenimento, apontam para a necessidade de se repensar a constituição e a reformulação da cultura capaz de caracterizar identidades. Como tratado por Santos (1994) e Hall (2003), não apenas a homogeneização como a diferenciação são ações comuns que os sujeitos da atualidade buscam para incorporar individualidade e coletividade a suas identidades. Assim, conclui-se que os social games (a partir do estudo e caso do FarmVille) podem ser potenciais ferramentas de divulgação, manifestação e formações da identidade cultural do sujeito da atualidade que ficam visíveis em suportes acessados pelas mais variadas culturas do mundo.

\section{REFERÊNCIAS}

ALBAGLI, Sarita. Território e Territorialidades. In LAGES Vinícios; BRAGA, Christiano; MORELLI, Gustavo (Org.). Territórios em movimento: cultura e identidade como estratégia de inserção competitiva. Sachs Prefácio, Rio de Janeiro: Relume Dumará/Brasília DF: Sebrae, 2004. 350 p.

BARROS FILHO, C.; LOPES, F.; ISSLER, B. Comunicação do Eu: Ética e solidão. Petrópolis, RJ: Vozes, 2005.

BOURDIEU, Pierre. O mercado dos bens simbólicos. In: A economia das trocas simbólicas. (org. Sérgio Miceli). São Paulo: Perspectiva, 1974. Pp. 99-181.

BOYD, D.; ELLISON, N. 2007. Social network sites: Definition, history, and scholarship. Journal of Computer-Mediated Communication, 13(1). Disponível em:

<http://jcmc.indiana.edu/vol13/issue1/boyd.ellison.html>. Acesso em: 20 jan 2009.

CASTELLS, Manuel. A Era da Informação: Economia, Sociedade e Cultura. Volume I. A Sociedade em Rede. São Paulo, Paz e Terra, 1999. 
COCKBURN, Cynthia. El circuito de la tecnologia. Gênero, identidad y poder. In: SILVERSTONE, R.; HIRSCH, E. (Ed.). Los efectos de la nueva comunicación: el consumo de la moderna tecnologia en el hogar y en la família, 1996.

DURHAM, Eunice. A dinâmica cultural na sociedade moderna. Ensaios de Opinião, Rio de Janeiro, 4, 1977.

FEATHERSTONE, Mike. Cultura do Consumo e Pós-modernismo. Tradução de Júlio Assis Simões. São Paulo: Studio Nobel, 1995.

HALL, Stuart. A Identidade Cultural na Pós-modernidade. Rio de Janeiro: DP\&A, 2000.

. Da diáspora: identidades e mediações culturais. Belo Horizonte: Brasília, Editora UFMG/UNESCO, 2003. p.51-128.

HAESBAERT. O mito da desterritorialização: do "fim dos territórios" à multiterritorialidade. 3 ed. Rio de Janeiro: Bertrand Brasil, 2007. 395 p.

HAUG, Wolfgang Fritz. Critica à estética da mercadoria. São Paulo: Fundação editora da UNESP, 1997.

HUIZINGA, Johann. Homo Ludens: O jogo como elemento da cultura. São Paulo: Perspectiva. 2000.

LACLAU, Ernesto. Emancipación y diferencia. Buenos Aires: Ariel, 1996.

LEMOS, A. Apropriação, desvio e despesa na cibercultura. Revista FAMECOS: mídia, cultura e tecnologia, Brasil, v. 1, n. 15, 2006. Disponivel em:

<http://www.revistas.univerciencia.org/index.php/famecos/article/view/282/214>. Acessado em: 19 jan 2011.

MARTÍN BARBERO, Jésus. Tecnicidades, identidades, alteridades: mudanças e opacidades da comunicação no novo século. In: MORAES, D. (org.). Sociedade Midiatizada. Trad. Carlos Moura da Silva, Maria Inês Coimbra Guedes, Lucio Pimentel. Rio de Janeiro: Mauad, 2006. p. 5179.

. As Formas Mestiças da Mídia. In: Pesquisa Online FAPESP. Edição Impressa 163 Setembro 2009. Disponível em: <http://revistapesquisa.fapesp.br/?art=3933\&bd=1\&pg=1>. Acesso em: 13 dez 2010.

MATA, Maria Cristina. Interrogaciones sobre el público. In: LOPES, Maria Immacolata y FUENTES, Raúl (comps) (2001): Comunicación, campo y objeto de estudio. México: ITESO/Universidad Autônoma de Aguacalientes/Universidad de Colima/Universidad de Guadalajara, 2001. pp. 183-199.

PRIMO, Alex. Interações Mediadas por Computador. Comunicação, cibercultura, cognição. Porto Alegre: Sulina. 2007.

REBS, Rebeca Recuero. O lugar no espaço virtual: um estudo etnográfico sobre as recriações de territórios do mundo concreto no Second Life. Dissertação de mestrado. Programa de Pós-Graduação em Ciências da Comunicação da Universidade do Vale do Rio dos Sinos, São Leopoldo, 2010.

Bens Virtuais em social games. Anais da XX COMPÓS (XX Encontro da Associação

Nacional dos Programas de Pós-Graduação em Comunicação). 2011. Disponível em: < http://www.compos.org.br/data/biblioteca_1575.docx>. Acesso em: 16 abr 2011. 
RECUERO, Raquel. Avatares - Viajantes entre os mundos. Artigo apresentado como requisito parcial à aprovação na disciplina de Novas Tecnologias da Comunicação e da Informação,ministrada pela profa. Dra. Marília Levacov, no PPGCOM/UFRGS, em julho de 2000. Disponível em:

<http://pontomidia.com.br/raquel/avatares.htm>. Acesso em 7 out 2008.

Redes Sociais na Internet. Porto Alegre, 2009. Sulina, 191 p.

RAO, V. Facebook Applications and Playful Mood: the Construction of Facebook as a "Third Place". Artigo apresentado na MindTrek'08, October 6-9, 2008, Tampere, Finland.

SANTOS, 1994. SANTOS, Boaventura de Souza. A gramática do tempo: para uma nova cultura política. 2. ed. São Paulo: Cortez, 2008.

SCHERER-WARREN, Ilse. Cidadania sem fronteiras. São Paulo: Hucitec, 1999. P. 1-95.

SCOTT, Lasch. Formas tecnológicas de vida (cap. 2) e Teoría mediática (cap. 6). In: SCOTT, Lasch. Critica de la información. Buenos Aires: Amorrortu, 2005, p. 39-58; p.119-138.

SILVA, Tomaz Tadeu da. A produção social da identidade e da diferença. In: SILVA, Tomaz Tadeu da (org.). Identidade e diferença. A perspectiva dos Estudos Culturais. Petrópolis, Vozes, 2007, pp. 73-102.

TAUSEND, U. Casual games and gender. 2006. Disponível em <http://www.ulrichtausend.com/research/Casual\%20Games\%20and\%20Gender\%20\%20Ulrich\%20Tausend.pdf> Acesso em: 01 maio 2010.

TURKLE, Sherry. A vida no ecrã: a identidade na era da Internet. Lisboa: Rel.D’água, 1997.

Original recebido em: 07/09/2013

Aceito para publicação em: Novembro de 2013

Rebeca Recuero

É pesquisadora em Cibercultura, doutoranda em Ciências da Comunicação, mestre em Ciências da Comunicação, graduada em Comunicação Social e em Medicina Veterinária. 